Review

\title{
The Impact of SGLT2i Therapy on the Onset and Prognosis of Heart Failure in Patients with Type 2 Diabetes
}

\author{
Bogdan Timar ${ }^{1}$, Adina Braha ${ }^{1, *}$, Lucica Grigorică ${ }^{2}$, Laura Gaiță ${ }^{1}$ and Romulus Timar ${ }^{1}$

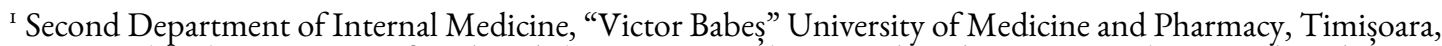 \\ Romania; bogdan.timar@umft.ro(B.T.); laura_gaita@yahoo.com (L.G.); timarrz@yahoo.com (R.T.) \\ ${ }^{2}$ Department of Cardiology, "Sf. Apostol Andrei” Clinical Emergency Hospital Galați, Romania; \\ luci22grigorica@yahoo.com \\ *Correspondence: braha.adina@umft.ro
}

Submitted: I4 September 2020; Accepted: 28 September 2020; Published: 19 October 2020

\begin{abstract}
The prevention of heart failure (HF) development in patients with diabetes mellitus (DM) represents one of the greatest challenges to date. Several studies have shown that targeting a very strict HbAic does not reduce cardiovascular risk in type 2 diabetes $\left(T_{2} D\right)$ patients, concluding that there are additional factors that contribute to the risk of HF, as well as mechanisms possibly related to the therapeutic agents used to lower glycemic values. All these findings led to the reconsideration of $\mathrm{T}_{2} \mathrm{D}$ management. SGLT2 inhibitors (SGLT2i), a new generation of antihyperglycemic drugs, have gained the attention of cardiologists, since they proved cardioprotective effects by reducing three-point major adverse cardiovascular events (MACE) and heart failure hospitalizations in $\mathrm{T}_{2} \mathrm{D}$ patients. The mechanisms underlying the cardiovascular protection of SGLT $T_{2}$ inhibitors in $\mathrm{T}_{2} \mathrm{D}$ are complex and multifactorial, but not fully understood. This review discusses the onset and prognosis of heart failure in $\mathrm{T}_{2} \mathrm{D}$ patients treated with SGLT2 inhibitors.
\end{abstract}

Keywords: heart failure; diabetes; SGLT2 inhibitors; CVOT trials

How to cite: Timar, B.; Braha, A.; Grigorică, L.; Gaiță, L.; Timar, R. The Impact of SGLT2i Therapy on the Onset and Prognosis of Heart Failure in Patients with Type 2 Diabetes. Timisoara Med. 2020, 2020(I), I; doi:I0.35995/tmj20200IOI.

\section{Introduction}

Heart failure (HF) has marked a progressive increase over the past decades, mostly due to the increase in life expectancy of the population and the incidence of obesity and diabetes mellitus (DM). Affecting over 26 million people worldwide, HF has an incidence of almost $2 \%$ in the general population and more than Io\% in the over 70 age group. Despite the treatments and devices available today, the morbidity and mortality of this clinical condition remain high. Data show that HF can be a clinical condition that is more malignant than some cancers. Thus, the 5-year survival rates from the diagnosis of HF can be more severe than those estimated in breast cancer or colorectal cancer in women over 70 years old, or in prostate or colorectal cancer in men within the same age group [I]. With a pandemic-like spread, increasing from decade to decade, $\mathrm{DM}$ contributes to an increasing number of HF cases, both medical conditions becoming serious public 
health issues and a financial burden for all healthcare systems. Recent data indicate that approximately $44 \%$ of patients with HF that needed admission had DM, and $\mathrm{I} 8 \%$ of patients that underwent transplant were patients with DM $[2,3]$. The coexistence of the two conditions consequently becomes one of the biggest medical challenges we presently face.

The causality relation between DM and HF has been discussed for over 40 years. The prevalence of the latter within the segment of DM patients varies between $19 \%$ and $26 \%$, four times that of the general population segment [4-7]. The results of the Framingham Heart Study, involving 30 years of observation, are proof that DM is indeed a risk factor for HF. The discrepancies found between male and female patients are not entirely understood to this day, the risk for women being five times higher than that of individuals without DM. At the same time, men face a risk only twice as high compared to individuals without DM. Notably, this risk remains constant, regardless of the presence of high blood pressure, coronary artery disease, obesity, and dyslipidemia [8].

HF in patients with DM occurs as a result of complex alterations that occur at a systemic, myocardial, and cellular level. The structural and functional alterations could be caused by myocardial ischemia due to coronary atherosclerosis, which results from hyperglycemia and hyperinsulinemia, in the absence of significant epicardial coronary involvement. This clinical entity we nowadays call diabetic cardiopathy was first mentioned by professor Lundbaeck in 1954 and has been of great scientific interest lately [9]. Diabetic cardiomyopathy is defined by the presence of structural and functional anomalies in the absence of coronary artery disease, high blood pressure, significant valvulopathies, or alcohol consumption according to ACC/AHA/ESC definitions from 20I3. During a myocardial infarction of the same size, a patient with DM has a much higher risk of developing HF compared to a patient without DM, supporting the idea that many times, overlapping situations do occur (diabetic cardiomyopathy and coronary ischemia can coexist at any given point), resulting in a more severe and accelerated contractile deterioration.

The HF classification based on ejection fraction was updated in 2016 when the European Society of Cardiology recommended three terminologies: HF with preserved ejection fraction ( $\mathrm{EF} \geq 50 \%)$, HF with reduced ejection fraction $(\mathrm{EF}<40 \%$ ), and $\mathrm{HF}$ with mid-range ejection fraction ( $\mathrm{EF} 40 \%-49 \%)$ [10]. This new classification imposes the identification of different underlying conditions by the physician, underlines demographic characteristics, and the associations between certain comorbidities, being of great importance for the prognosis of these patients. By far, the essential difference between the three categories of HF is represented by their response to treatment. For HF with reduced ejection fraction, several pharmaceutical options significantly improve general and cardiovascular mortality, as well as the number of hospital admissions. Furthermore, several designed devices such as resynchronization therapy, cardiac defibrillators, cardiac contractility modulation devices, or ventricular assist devices have proven clear benefits for these patients. Unfortunately, in the case of HF with preserved ejection fraction, studies involving angiotensin enzyme inhibitors/angiotensin receptor blockers, beta-blockers, or mineralocorticoid receptor antagonists failed to convince on the endpoints mentioned above. The sacubitril/valsartan combination shows promise in the most recent study (PARALLAX), proving to be beneficial in those with an EF $>40 \%$ [II]. Data collected from registries show that most patients with DM and HF have a preserved systolic function ( $75 \%$ of cases), with treating these patients becoming particularly challenging and complicated [I2].

The relation between HF and DM is full of interferences, presenting many pathophysiological similarities. The incidence of DM among patients with HF is higher than in the general population, correlating with the insulin resistance found in these patients. The main predictors of the development of DM in patients with $\mathrm{HF}$ are: increased BMI, increased abdominal girth, smoking, an increase in HbAic values, a history of high 
blood pressure, the duration of HF, the severity of the NYHA functional class, and the prolonged use of loop diuretics [13,14].

The prevention of HF development in patients with DM represents one of the greatest challenges to date. Increased levels of $\mathrm{HbAic}$ are associated with an increased risk of $\mathrm{HF}$ [is].

The results of some important clinical trials (Table I) come as proof that a strict glycemic control to mimic normal values does not decrease the patient's cardiovascular risk to that of a person without DM. Although in the endpoints of these studies, HF was not encountered, post hoc analysis has shown that intensive glycemic control did not reduce the HF risk, nor the number of hospital admissions for this condition [16].

Table 1. Evidence of clinical trials with cardiovascular outcomes.

\begin{tabular}{ll}
\hline Clinical Trial & Results \\
\hline UKPDS $^{\text {a }}$ & A reduction in HbAic by i\% reduces the risk for HF by $\mathrm{I} 6 \%$ [17] \\
ADVANCE $^{\mathrm{b}}$ & $\begin{array}{l}\text { HbAic reduction to levels around 6.5\% did not prove to induce an additional } \\
\text { reduction in macrovascular complications, nor did it increase mortality within the } \\
\text { strict glycemic control group [16] }\end{array}$ \\
\hline
\end{tabular}

${ }^{a}$ The UK Prospective Diabetes Study; ${ }^{b}$ Action in Diabetes and Vascular Disease: Preterax and Diamicron MR Controlled Evaluation.

It has become apparent that there are additional factors that contribute to the risk of HF, as well as mechanisms possibly related to the therapeutic agents used to lower glycemic values. This idea led to the conclusion that treatments used in patients with DM should not be solely chosen with glucose values in mind. Direct or indirect mechanisms have been identified by which antihyperglycemic agents may intervene in myocardial remodeling and injury regardless of their blood glucose-lowering effect. The first line of treatment for the patient that has DM and HF, or an increased risk of HF, should consist of a medication that decreases the risk of HF or that will not sustain the progression of HF. At the same time, it was suggested that the HbAic targets should be individualized according to the severity of the HF and the patient's comorbidities.

Patients with HF and DM have a more severe prognosis than those with HF without DM. The association of these two clinical conditions increases cardiovascular mortality, including that caused by worsening heart failure by $50-90 \%$ regardless of the ejection fraction, and the number of hospitalizations by $50 \%$ [ $18-20]$.

We are looking optimistically to new therapeutic drugs, such as the sacubitril/valsartan combination, and therefore, we can extend the optimism to SGLT2 inhibitors, which provide consistent proof that will undoubtedly change the treatment algorithm of patients with HF and DM.

\section{Cardiovascular Outcome Trials and Mechanisms of Action of SGLT2 Inhibitors}

Although the association of DM and cardiovascular disease (CVD) was already well known, it was only in 2008 that the U.S. Food and Drug Administration (FDA) issued guidance to the pharmaceutical industry for the development of antihyperglycemic drugs for type $2 \mathrm{DM}\left(\mathrm{T}_{2} \mathrm{D}\right)$. This decision was followed by the European Medicines Agency (EMA), requiring that all these agents should undergo a rigorous assessment of CV safety through large-scale cardiovascular outcome trials (CVOTs) [21,22]. Therefore, authorities considered $\mathrm{CV}$ death, non-fatal stroke, or non-fatal myocardial infarction as a three-point major adverse $\mathrm{CV}$ event (3P-MACE) in the CVOTs for antidiabetic drugs [23]. 
$S_{\text {GLT }} 2$ inhibitors were introduced in the management of $\mathrm{T}_{2} \mathrm{D}$ in 2013 and showed cardioprotective effects by reducing the three-point MACE, as shown in the latest clinical trials (Table 2). SGLT2 inhibitors are a new generation of antihyperglycemic drugs that lower blood sugar by causing an approximate daily $70 \mathrm{~g}$ urinary glucose excretion with a consecutive increase in diuresis by $200-300 \mathrm{~mL}$, independent of beta-cell function, with a decrease in HbAic up to 0.5-1.5\% [24]. Usually, the kidneys filter glucose from the blood, which is then reabsorbed back into the bloodstream. Proteins that perform glucose reabsorption are called sodium-glucose transporter proteins. SGLT2 inhibitors block some of the proteins, a process that allows the kidneys to lower blood glucose levels and eliminate excess glucose from the blood through the urine [25]. In addition, by removing glucose from the body, $\mathrm{SGLT}_{2}$ inhibitors have a beneficial weight loss effect (triggered by a loss of about 280 kilocalories daily) and glucose-induced osmotic diuresis [26]. However, this class of drugs has specific side effects, such as an increased risk of genital and urinary tract infections and, in rare cases, diabetic ketoacidosis at lower glycemic values than usually expected [23,27-29].

The first SGLT2 inhibitor that proved CV benefits in a large CVOT was empagliflozin. In EMPA-REG OUTCOME, a large number of patients with $\mathrm{T}_{2} \mathrm{D}$ and established CVD were enrolled (coronary, peripheral, or cerebrovascular disease), who were randomly assigned to be treated with io or $25 \mathrm{mg}$ of empagliflozin or placebo. After a median 3.I years follow-up, empagliflozin showed not only a reduction in 3P-MACE by I $4 \%$ compared to the placebo but also a significant reduction of $38 \%$ in cardiovascular mortality, of $32 \%$ in all-cause mortality, respectively, and of $35 \%$ in hospitalization for heart failure [30]. Additionally, data from the EMPA-REG OUTCOME suggested that changes in plasma volume were the most crucial factor in reducing the risk of cardiovascular death with empagliflozin compared to the placebo [3I].

Similar benefits were shown by another SGLT2 inhibitor, canagliflozin, in the CANVAS Program, which included two major clinical trials, CANVAS and CANVAS-Renal. A total of $66 \%$ of patients with $\mathrm{T}_{2} \mathrm{D}$ included in the CANVAS trial also had CVD, unlike the previously mentioned study where more than $99 \%$ of patients had cardiovascular disease. Included patients were aged $\geq 30$ years, with a $\mathrm{HbArc} \geq 7 \%$ and less than $10.5 \%$ and history of symptomatic atherosclerotic CVD, or aged over 50 years with more than two CV risk factors $\left(\mathrm{SBP}>\mathrm{I} 4 \mathrm{O} \mathrm{mmHg}\right.$, eGFR $>30 \mathrm{~mL} / \mathrm{min} / \mathrm{r} .73 \mathrm{~m}^{2}$ ). This CVOT demonstrated that canagliflozin reduces 3 P-MACE, but has no significant effect on the reduction in all-cause mortality between the two groups (HR: 0.86 ; $95 \%$ CI: 0.75-0.97; $p<0.001$ for non-inferiority and $p=0.02$ for superiority) [23].

Similar to the previously mentioned studies, the DECLARE-TIMI 58 trial has proven that dapagliflozin significantly reduced mortality due to $\mathrm{CV}$ causes and reduced the rates of hospitalization due to heart failure (HR: 0.98 ; 95\% CI: $0.83-0.95 ; p=0.005$ ). However, the study has shown no significant effects on the ${ }_{3} \mathrm{P}-\mathrm{MACE}$ outcome in the DAPA group. The study included a larger number of $\mathrm{T}_{2} \mathrm{D}$ patients, among which $4 \mathrm{I} \%$ had established atherosclerotic CVD (ASCVD), while the others had multiple risk factors for ASCVD, which were randomized to receive either to mg dapagliflozin or placebo, for a median follow-up of 4.2 years $[32]$.

All of these findings led to a paradigm shift in $\mathrm{T}_{2} \mathrm{D}$ treatment. Through their unique mechanism of action, independent of the beta-cellular function of the pancreas, SGLT2 inhibitors have proven cardiorenal protection. The previously mentioned reduction in hospitalizations for heart failure observed in studies with cardiorenal targets in patients with $\mathrm{T}_{2} \mathrm{D}$ was due to the effect of SGLT $2 \mathrm{i}$ producing osmotic diuresis and natriuresis, and as a consequence, decreasing in preload and pulmonary congestion, as well as in systemic edema [33]. A notable effect mediated by these molecules is the inhibition of the NHEI antiporter, which determines the reduction in sodium and calcium levels at the cytoplasmic level and increases calcium levels at the mitochondrial level [34-36]. SGLT2 inhibitors reduce cardiac overload by lowering blood pressure 
without increasing heart rate, even in patients with low glomerular filtration rate, suggesting that they decrease the action of the sympathetic nervous system in heart failure [37,38]. Besides, studies have shown that SGLT2i improves the mechanical efficiency of the myocardium by producing ketone bodies, namely beta-hydroxybutyrate, which is preferentially oxidized by the heart [39]. Another mechanism underlying the cardiorenal protection of SGLT2 inhibitors is erythrocytosis by stimulating renal erythropoietin secretion. Through this mechanism, SGLT2 inhibitors attenuate metabolic stress in renal cells and inhibit the sympathetic nervous system response [40]. It should not be overlooked that they reduce inflammation and improve mitochondrial function $[4 \mathrm{I}, 42]$.

However, the studies and evidence did not stop here. In June 2020, at the 8oth Scientific Sessions of the American Diabetes Association, the results of another CVOT were revealed, those of the VERTIS-CV trial (eValuation of ERTugliflozin efficacy and Safety CardioVascular outcomes trial) with the SGLT2i ertugliflozin. The primary study aim was to demonstrate the non-inferiority of ertugliflozin versus placebo on major adverse $\mathrm{CV}$ events, a composite of $\mathrm{CV}$ death, non-fatal myocardial infarction (MI), and non-fatal stroke, while the secondary objectives were to demonstrate the superiority of ertugliflozin versus placebo regarding the composite outcome of CV death or hospitalization for $\mathrm{HF}, \mathrm{CV}$ death, and the first event of renal death, dialysis/transplant, or doubling of serum creatinine from baseline. Moreover, all of the enrolled patients were over 40 years old with $\mathrm{T}_{2} \mathrm{D}$ and established atherosclerotic cardiovascular disease (ASCVD) involving the coronary, cerebrovascular, and/or peripheral arterial systems [43].

The results have shown that the primary objective of the non-inferiority of ertugliflozin versus placebo on major adverse $\mathrm{CV}$ events was met (HR 0.97, 95\% CI 0.85-I.II, $p<0.00$ I for non-inferiority), demonstrating the $\mathrm{CV}$ safety of this SGLT2i. The secondary endpoints that were aiming for superiority regarding the composite of $\mathrm{CV}$ death/hospitalization for $\mathrm{HF}$ ( $\mathrm{HR} 0.88,95 \% \mathrm{CI} 0.75-\mathrm{I} .03, p=0.1 \mathrm{I}$ for superiority), $\mathrm{CV}$ death (HR 0.92, 95\% CI o.77-I.II, $p=0.39$ ), and the renal composite (HR 0.8I, 95\% CI o.63-I.04, $p=0.08$ ) did not show statistical significance. However, another prespecified endpoint, the effect of ertugliflozin versus placebo regarding hospitalization for heart failure, has proven the statistically significant superiority of ertugliflozin ( $\mathrm{HR} 0.90,95 \% \mathrm{CI} 0.54-0.90, p=0.006$ ), results that prove consistent effects across the class of SGLT2i [44].

The latest agent in the class, sotagliflozin, is the first dual sodium-glucose co-transporter-2 and I inhibitor, meaning that its mechanisms involve not only the urinary excretion of glucose, similarly to other drugs, but also the intestinal absorption of glucose, with effects on postprandial glycemic levels. The inhibition of both SGLT2 and SGLTI would also lead to an increased glycosuric effect-the SGLT2 is responsible for the reabsorption of approximately $90 \%$ of the filtered glucose, with the remaining being reabsorbed by the SGLTI that presumably presents a compensatory action with the inhibition of the former [45]. Moreover, SGLTI is reported to be highly expressed in both human autopsied hearts and murine perfused hearts [46,47]. These findings alongside a study that analyzed the effects of loss-of-function mutations in the SGLTi gene that has shown a decrease in the incidence of DM, of HF, and even of mortality suggest long-term protective effects of this new agent on cardiometabolic outcomes [48].

However, the phase 3 study that is evaluating the effects of sotagliflozin-SCORED (Effect of Sotagliflozin on Cardiovascular and Renal Events in Patients with Type 2 Diabetes and Moderate Renal Impairment Who Are at Cardiovascular Risk) -is still ongoing, with an estimated completion date of January 2022. Its primary objectives are to demonstrate that when compared to placebo in patients with $\mathrm{T}_{2} \mathrm{D}, \mathrm{CV}$ risk factors, and moderately impaired renal function, sotagliflozin does not increase the risk of $\mathrm{CV}$ events, including death 
from CVD, non-fatal heart attack, and non-fatal stroke and that it reduces the risk of death from CV disease or hospitalization for heart failure [49].

Table 2. Cardiovascular outcome trials of SGLT2 inhibitors in type 2 diabetes $\left(\mathrm{T}_{2} \mathrm{D}\right)$ patients.

\begin{tabular}{lcll}
\hline Clinical Trial & SGLT2i & Characteristics & Results \\
\hline $\begin{array}{l}\text { EMPA-REG } \\
\text { OUTCOME }\end{array}$ & Empagliflozin & Established CVD & $\begin{array}{l}\text { Reduction in 3P-MACE, CV mortality, all-cause } \\
\text { mortality, and HFH [30] }\end{array}$ \\
\hline CANVAS & Canagliflozin & $\begin{array}{l}\text { 66\% of included patients } \\
\text { had CVD }\end{array}$ & $\begin{array}{l}\text { Reduction in 3P-MACE, but no significant effect } \\
\text { in all-cause mortality [23] }\end{array}$ \\
\hline DECLARE-TIMI 58 & Dapagliflozin & $\begin{array}{l}41 \% \text { of included patients } \\
\text { had ASCVD }\end{array}$ & $\begin{array}{l}\text { Reduction in CV mortality and in HFH rates, no } \\
\text { significant effects on the 3P-MACE outcome [32] }\end{array}$ \\
\hline VERTIS-CV & Ertugliflozin & Established ASCVD & $\begin{array}{l}\text { Non-inferiority on major adverse CV events (CV } \\
\text { death, non-fatal myocardial infarction, and } \\
\text { non-fatal stroke) [43] }\end{array}$ \\
\hline SCORED & Sotagliflozin & $\begin{array}{l}\text { CV risk factors and moderately } \\
\text { impaired renal function }\end{array}$ & Estimated completion date of January 2022 [49] \\
\hline
\end{tabular}

The results of these CVOTs have led to changes in international guidelines. Whereas in 2017, SGLT2i were considered one of the multiple options for dual antihyperglycemic therapy in association with metformin, in 2018, the $\mathrm{ADA}$ guidelines included the recommendation of associating with metformin as a second-line therapy, an agent proven to reduce major adverse $\mathrm{CV}$ events and $\mathrm{CV}$ mortality [50]; meanwhile, in the month of October of the same year, the Consensus Report by the American Diabetes Association (ADA) and the European Association for the Study of Diabetes (EASD) added a different algorithm for the approach of $\mathrm{T}_{2} \mathrm{D}$ based on the individualization of antihyperglycemic treatment. The recommended first-line therapy in this consensus is still represented by metformin alongside lifestyle changes; however, the second-line agent is chosen taking into consideration the presence or absence of ASCVD or chronic kidney disease (CKD), in their presence the predominating condition such as ASCVD or HF/CKD and in their absence the major goal, be it to minimize hypoglycemia, to minimize weight gain or the promotion of weight loss, and, lastly, the reduction in costs. SGLT $2 i$ are one of the two recommendations for second-line treatment in ASCVD and one of the options for the second-line drug in all patients without ASCVD or CKD, with the only exception for situations when cost is a major issue for the management of the patient. However, SGLT2i are the definite preferred option for second-line treatment in patients with established ASCVD or CKD if the HF or the CKD predominates [ $[5]$.

The 2019 update of this Consensus and the 2020 recommendations of the American Diabetes Association emphasized even more the importance of new classes of antidiabetic drugs, the SGLT2i and the GLP-I receptor agonists. The documents mention that high-risk patients (not only those with established ASCVD or CKD) should be treated with a GLP-I RA or an SGLT2i to reduce MACE, hospitalization for HF, cardiovascular death, and the progression of $\mathrm{CKD}$ and that their use should be considered independently of the baseline HbAic or of the HbAic target. Furthermore, it is specified that SGLT2i-with a preference for empagliflozin, canagliflozin, and dapagliflozin — are recommended in $\mathrm{T}_{2} \mathrm{D}$ patients with $\mathrm{HF}$, particularly those with HFrEF, to reduce hospitalization for HF, MACE, and CVD death as well as in patients with $\mathrm{T}_{2} \mathrm{D}$ and CKD [52,53]. Moreover, the 2019 ESC Guidelines on diabetes, pre-diabetes, and cardiovascular diseases developed in collaboration with the EASD also mention that SGLT2i, namely empagliflozin, canagliflozin, or dapagliflozin, are recommended to lower the risk of HF hospitalization and to reduce the progression of CKD and even suggest using an SGLT2i or a GLP-I RA as monotherapy in drug-naïve patients with 
$\mathrm{T}_{2} \mathrm{D}$ and $\mathrm{ASCVD}$ or high/very high CV risk in order to reduce CV events (empagliflozin, canagliflozin, or dapagliflozin) and to reduce the risk of death in patients with T2D and CVD (empagliflozin) [20].

\section{Heart Failure Trials with SGLT2 Inhibitors}

The consistent and statistically significant results from the aforementioned CVOTs regarding reductions in the hospitalization for heart failure and the ongoing research about the mechanisms of the SGLT2i have led to continuously increasing interest about the possible beneficial effects of these agents in patients with heart failure, with or without DM.

The first trial to investigate these effects, DAPA-HF (Dapagliflozin and Prevention of Adverse Outcomes in Heart Failure) included patients at least I8 years old with an ejection fraction of $40 \%$ or less, with New York Heart Association (NYHA) class II-IV symptoms and with NT-proBNP of $600 \mathrm{pg} / \mathrm{mL}$ or more (if hospitalized for $\mathrm{HF}$ within the last $\mathrm{I} 2 \mathrm{months}, 400 \mathrm{pg} / \mathrm{mL}$ or more, and if they also had atrial fibrillation or flutter or $900 \mathrm{pg} / \mathrm{mL}$ or more). The primary outcome of this trial was a composite of worsening HF-either an unplanned hospitalization or an urgent visit resulting in intravenous therapy for $\mathrm{HF}$-or death from $\mathrm{CV}$ causes, while the key secondary outcome was a composite of hospitalization for heart failure or $\mathrm{CV}$ death. Of all the patients in each trial group, $42 \%$ had a history of $\mathrm{T}_{2} \mathrm{D}$ and an additional $3 \%$ received a new diagnosis of DM. The results have shown that dapagliflozin reduced the risk of the composite of death from CV causes, hospitalization for $\mathrm{HF}$, or an urgent visit resulting in intravenous therapy for $\mathrm{HF}$ ( $\mathrm{HR} 0.74,95 \% \mathrm{CI} 0.65-0.85$, $p<$ o.ooI). Furthermore, each of the three components of the composite outcome was less common in the dapagliflozin group, while the use of this agent resulted in a clinical improvement of heart failure as measured on the Kansas City Cardiomyopathy Questionnaire. It is of paramount importance that these beneficial effects have been demonstrated both in patients with and without $T_{2} D$, findings that once again suggest that the impact of SGLT2i lies far beyond the glucose-lowering effects [54].

Moreover, the New Onset Diabetes Sub-study has shown that dapagliflozin reduced the incidence of $\mathrm{T}_{2} \mathrm{D}$ by $32 \%$, results mainly driven by participants with prediabetes, and, thus, is the first SGLT2i trial to show a potential diabetes prevention effect, although further studies are needed for a better understanding of this discovery [55]. Regarding the concerns about potential adverse events, these were proven to be infrequent and to occur with a similar incidence in both arms, including volume depletion, renal dysfunction, fractures, amputations, major hypoglycemia, ketoacidosis, or Fournier's gangrene [56].

The results from DAPA-HF regarding the favorable impact of dapagliflozin on the Kansas City Cardiomyopathy Questionnaire score are similar to those from the DEFINE-HF Trial (Dapagliflozin Effects on Biomarkers, Symptoms and Functional Status in Patients with HF with Reduced Ejection Fraction). The latter, a trial that included patients with HF and LVEF of $40 \%$ or less, NYHA class II-III, eGFR of 30 $\mathrm{mL} / \mathrm{min} / \mathrm{r} .73 \mathrm{~m}^{2}$ or higher, and elevated natriuretic peptides (NT-proBNP of $400 \mathrm{pg} / \mathrm{mL}$ or higher or BNP of Ioo $\mathrm{pg} / \mathrm{mL}$ or higher) has also suggested that a greater proportion of patients treated with dapagliflozin for I2 weeks had a clinically meaningful improvement of 5 or more points in the Kansas City Cardiomyopathy Questionnaire (KCCQ) Overall Summary Score or at least a $20 \%$ reduction in NT-proBNP as compared with the placebo. Furthermore, these beneficial effects were consistent within subgroups of patients with or without $\mathrm{T}_{2} \mathrm{D}$. However, the DEFINE-HF Trial has not shown between-group differences in patients treated with dapagliflozin versus placebo regarding the average 6- and I2-week adjusted mean NT-proBNP, although the proportion of patients with a $20 \%$ or higher decrease in NT-proBNP and BNP at the end of the treatment period, two secondary outcome measures, were higher in patients treated with dapagliflozin, and, thus, further studies are needed to establish the mechanisms behind these findings [ 57 ]. 
The DEFINE-HF Trial is just one of the several studies included in the series named DAPAMECH whose goal is to continue to advance the understanding of the underlying science behind the CV and renal effects of dapagliflozin, including the mechanisms that make SGLT2i "smart diuretics" [58,59]. The series also includes, among others, the ongoing PRESERVED-HF trial (Dapagliflozin in PRESERVED Ejection Fraction Heart Failure) that will complement the data from DAPA-HF with results about the changes from baseline in NTproBNP and other HF-related measurements in patients with HFpEF.

This August (2020), the results from the EMPEROR-Reduced Trial (Empagliflozin Outcome Trial in Patients with Chronic Heart Failure and a Reduced Ejection Fraction) were published and presented in the ESC Congress. The study included patients of at least $\mathrm{I} 8$ years in age with chronic HF and a NYHA functional class of II-IV, with a LVEF of $40 \%$ or less, with a HF hospitalization within I2 months if the EF was higher than $30 \%$, or with NT-proBNP levels of $600 \mathrm{pg} / \mathrm{mL}$ or higher if $\mathrm{EF}$ was $\leq 30 \%$, of $1000 \mathrm{pg} / \mathrm{mL}$ or higher if the $\mathrm{EF}$ was $3 \mathrm{I}-35 \%$, or of $2500 \mathrm{pg} / \mathrm{mL}$ or higher if the $\mathrm{EF}>35 \%$ (with doubled thresholds if concomitant atrial fibrillation was present). The primary outcome was a composite of cardiovascular death or hospitalization for heart failure analyzed as the time to the first event, while the secondary endpoints were represented by the total (first and recurrent) heart failure hospitalizations and by the slope of decline in glomerular filtration rate over time. It is important to notice that half of the enrolled patients-similar to the DAPA-HF trial—had DM.

The results have shown that empagliflozin reduced the risk of the composite of death from $\mathrm{CV}$ causes or hospitalization for heart failure ( $\mathrm{HR} 0.75,95 \% \mathrm{CI} 0.65-0.86, p<0.00 \mathrm{I})$. The two prespecified secondary outcomes were also favorably influenced, while all of these benefits were seen in patients with or without diabetes mellitus or, even more clearly than in DAPA-HF, in those treated with sacubitril/valsartan and in those without this combination. Furthermore, similar to the DAPA-HF trial, the treatment with empagliflozin improved the scores measured on the KCCQ. The potential difference in CV mortality noticed between the DAPA-HF trial (HR 0.82, 95\% CI 0.69-0.98) and the EMPEROR-Reduced trial (HR 0.92, 95\% CI $0.75^{-I . I 2}$ ) could be explained by an array of different reasons-including the heterogeneity of drugs and the increased severity of HF in the latter-however, a head-to-head comparison would be needed for an appropriate conclusion [6o-62]. Further results about the effects of empagliflozin on heart failure are going to be published after the termination of several ongoing trials, including EMPEROR-Preserved that will complement the data from EMPEROR-Reduced with information about the time to the first event of adjudicated CV death or HFH in patients with HFpEF [63].

The heart failure clinical trials with SGLT2i are presented in Table 3.

Therefore, in 2020, the European Society of Cardiology and the Heart Failure Association published a position paper on the role and safety of new glucose-lowering drugs in patients with heart failure. This document summarizes the relevant clinical trial evidence concerning the SGLT2i, GLP-I RA and DPP-4i. Furthermore, it mentions that the significant reduction in cardiovascular mortality and HF events in patients with HFrEF, with or without $\mathrm{T}_{2} \mathrm{D}$, that has been shown in DAPA-HF (the only HF trial completed at that time) together with the ongoing clinical trials (including EMPEROR-Reduced at that moment) would lead to determining whether SGLT2i could be used for the treatment of HF, with or without reduced LVEF and whether their beneficial CV effects could be extended to HF patients without $\mathrm{T}_{2} \mathrm{D}$ [20]. Moreover, in May 2020, the U.S. Food and Drug Administration approved dapagliflozin for adults with HF with reduced ejection fraction and NYHA functional class II-IV to reduce the risk of CV death and hospitalization for HF $[64,65]$. 
Table 3. Heart failure trials with SGLT2 inhibitors.

\begin{tabular}{|c|c|c|c|}
\hline Clinical Trial & SGLT2i & Characteristics & Results \\
\hline DAPA-HF & Dapagliflozin & $\begin{array}{l}42 \% \text { patients with } T_{2} D, 3 \% \text { received a } \\
\text { new diagnosis of } \mathrm{DM}\end{array}$ & $\begin{array}{l}\text { Reduced the risk of the composite of CV } \\
\text { death, } \mathrm{HFH} \text { both in patients with and } \\
\text { without } \mathrm{T}_{2} \mathrm{D}[55]\end{array}$ \\
\hline DEFINE-HF & Dapagliflozin & $\begin{array}{l}\text { Patients with } \mathrm{HF} \text { and } \mathrm{LVEF} \leq 40 \% \text {, } \\
\text { NYHA class II-III, eGFR } \geq \\
30 \mathrm{~mL} / \mathrm{min} / \mathrm{r} .73 \mathrm{~m}^{2} \text { or higher and } \\
\text { elevated natriuretic peptides }\end{array}$ & $\begin{array}{l}\text { A clinically meaningful improvement of } \\
5 \text { or more points in the KCCQ Overall } \\
\text { Summary Score or at least a } 20 \% \\
\text { reduction in NT-proBNP as compared } \\
\text { with placebo }[58]\end{array}$ \\
\hline EMPEROR-Reduced & Empagliflozin & $\begin{array}{l}\text { Chronic HF and a NYHA of II-IV, with } \\
\text { a LVEF } \leq 40 \%, 50 \% \text { of the enrolled } \\
\text { patients had DM }\end{array}$ & $\begin{array}{l}\text { Reduced the risk of the composite of CV } \\
\text { death or HFH, regardless of } \\
\text { sacubitril/valsartan therapy, in patients } \\
\text { with or without DM [6I-63] }\end{array}$ \\
\hline
\end{tabular}

Therefore, with the recent findings from the EMPEROR-Reduced trial, extremely consistent with the results from DAPA-HF and at the same time complementing them (patients lower LVEF and higher NT-proBNP in EMPEROR-Reduced versus DAPA-HF), it is no surprise that SGLT2i are considered as a potential new standard of care for patients with heart failure with reduced ejection fraction, with or without $\mathrm{T}_{2} \mathrm{D}[6 \mathrm{6}, 65]$. Furthermore, due to the fact that the three drug classes that were proven to reduce mortality in patients with HFrEF beyond conventional therapy consisting of ACE inhibitors or ARBs and beta-blockers, namely SGLT $2 \mathrm{i}$, mineralocorticoid receptor antagonists, and the association of angiotensin receptor antagonist and neprilysin inhibitors that have been studied with different background therapies, a cross-trial analysis from 2020 estimated lifetime gains in event-free survival and overall survival with comprehensive therapy versus conventional therapy. The results support the combination use of an ARNI, a beta-blocker, MRA, and SGLT2i as a new therapeutic standard, with an estimation of 2.7 additional years (for an 8o-year-old) to 8.8 additional years (for a 55-year-old) free from CV death or first hospital admission for heart failure and I.4 additional years (for an 80-year-old) to 6.3 additional years (for a 55-year-old) of survival in comprehensive disease-modifying pharmacological therapy versus conventional therapy [66].

It is expected that these results will lead to changes in current guidelines regarding the management of patients with HFrEF - the Canadian Cardiovascular Society and the Canadian Heart Failure Society have already recommended the use of SGLT2i in patients with mild or moderate heart failure who have an EF of $40 \%$ or less to improve symptoms and quality of life and to reduce the risk of hospitalization for HF and cardiovascular mortality $[67,68]$ - and that the ongoing studies about the effects of SGLT2i on HFpEF will fill the gaps of knowledge and will lead to a shift of paradigm in diabetology and cardiology.

\section{Conclusions}

At this point, after revealing the results of the latest clinical trials with SGLT2 inhibitors, the approach for the patient with CVD, HF, and reduced EF, with or without DM, needs to be reconsidered. SGLT2 inhibitors should be added to currently recommended treatments in patients with or without $\mathrm{T}_{2} \mathrm{D}$, with $\mathrm{HF}$, in line with the current evidence base and guidelines.

Author Contributions: Conceptualization, B.T. and R.T.; resources, A.B., L.G. (Lucica Grigorică) and L.G. (Laura Gaiță); writing—original draft preparation, B.T., A.B., L.G. (Lucica Grigorică), L.G. (Laura Gaiță), R.T.; writing-review and editing, B.T., A.B., L.G. (Lucica Grigorică), L.G. (Laura Gaiță), R.T.; visualization, B.T. and 
R.T.; supervision, B.T. and R.T.; project administration, B.T. All authors have read and agreed to the published version of the manuscript.

Funding: This research received no external funding.

Conflicts of Interest: The authors declare no conflict of interest.

$\begin{array}{ll}\text { Abbreviations } & \\ \text { ACC } & \text { American College of Cardiology } \\ \text { ADA } & \text { American Diabetes Association } \\ \text { AHA } & \text { American Heart Association } \\ \text { ARNI } & \text { Angiotensin receptor-neprilysin inhibitor } \\ \text { ASCVD } & \text { Atherosclerotic cardiovascular disease } \\ \text { CI } & \text { Confidence interval } \\ \text { CKD } & \text { Chronic Kidney Disease } \\ \text { CV } & \text { Cardiovascular } \\ \text { CVOT } & \text { Cardiovascular outcome trials } \\ \text { DM } & \text { Diabetes mellitus } \\ \text { DPP-4i } & \text { Dipeptidyl peptidase-4 inhibitors } \\ \text { EASD } & \text { European Association for the Study of Diabetes } \\ \text { EF } & \text { Ejection fraction } \\ \text { eGFR } & \text { Estimated glomerular filtration rate } \\ \text { ESC } & \text { European Society of Cardiology } \\ \text { FDA } & \text { Food and Drug Administration } \\ \text { GLP-I RA } & \text { Glucagon-like peptide-I receptor agonists } \\ \text { HbAic } & \text { Hemoglobin Aic } \\ \text { HF } & \text { Heart Failure } \\ \text { HFpEF } & \text { Heart failure with preserved ejection fraction } \\ \text { HFrEF } & \text { Heart failure with reduced ejection fraction } \\ \text { HFH } & \text { Heart Failure Hospitalization } \\ \text { HR } & \text { Hazard ratio } \\ \text { KCCQ } & \text { Kansas City Cardiomyopathy Questionnaire } \\ \text { LVEF } & \text { Left ventricle ejection fraction } \\ \text { MACE } & \text { Major adverse cardiovascular events } \\ \text { MR } & \text { Modified release } \\ \text { MRA } & \text { Mineralocorticoid receptor antagonists } \\ \text { NHE I } & \text { Sodium-hydrogen antiporter I } \\ \text { NT-proBNP } & \text { N-terminal pro brain natriuretic peptide } \\ \text { NYHA } & \text { New York Heart Association } \\ \text { SGLT2i } & \text { Sodium-Glucose co-transporter-2 inhibitors } \\ \text { T2D } & \text { Type 2 diabetes } \\ & \end{array}$

\section{References}

I. Stewart, S.; Ekman, I.; Ekman, T.; Odén, A.; Rosengren, A. Population Impact of Heart Failure and the Most Common Forms of Cancer. Circ. Cardiovasc. Qual. Outcomes 2010, 3, 573-58o. [CrossRef] [PubMed]

2. Echouffo-Tcheugui, J.B.; Xu, H.; Devore, A.D.; Schulte, P.J.; Butler, J.; Yancy, C.W.; Bhatt, D.L.; Hernandez, A.F.; Heidenreich, P.A.; Fonarow, G.C. Temporal trends and factors associated with diabetes mellitus among patients hospitalized with heart failure: Findings from Get With The Guidelines-Heart Failure registry. Am. Heart J. 2016, 182, 9-20. [CrossRef] [PubMed]

3. Russo, M.J.; Chen, J.M.; Hong, K.N.; Stewart, A.S.; Ascheim, D.D.; Argenziano, M.; Mancini, D.M.; Oz, M.C.; Naka, Y.; The Columbia University Heart Transplant Outcomes Research Group. Survival After Heart Transplantation Is Not Diminished Among Recipients with Uncomplicated Diabetes Mellitus. Circulation 2006, 114, 228o-2287. [CrossRef] [PubMed]

4. Ryden, L.; Armstrong, P.; Cleland, J.; Horowitz, J.; Massie, B.; Packer, M.; Poole-Wilson, P. Efficacy and safety of high-dose lisinopril in chronic heart failure patients at high cardiovascular risk, including those with diabetes mellitus. Results from the ATLAS trial. Eur. Heart J. 2000, 21, 1967-1978. [CrossRef] [PubMed]

5. Shindler, D.M.; Kostis, J.B.; Yusuf, S.; Quinones, M.A.; Pitt, B.; Stewart, D.; Pinkett, T.; Ghali, J.K.; Wilson, A.C.; The SOLVD Investigators. Diabetes mellitus, a predictor of morbidity and mortality in the studies of left ventricular dysfunction (SOLVD) trials and registry. Am. J. Cardiol. 1996, 77, , I017-1020. [CrossRef] 
6. Thrainsdottir, I.S.; Aspelund, T.; Thorgeirsson, G.; Gudnason, V.; Hardarson, T.; Malmberg, K.; Sigurdsson, G.; Rydén, L. The Association Between Glucose Abnormalities and Heart Failure in the Population-Based Reykjavik Study. Diabetes Care 2005, 28, 612-616. [CrossRef]

7. Nichols, G.A.; Gullion, C.M.; Koro, C.E.; Ephross, S.A.; Brown, J.B. The Incidence of Congestive Heart Failure in Type 2 Diabetes: An update. Diabetes Care 2004, 27, 1879-1884. [CrossRef]

8. Kannel, W.B. Diabetes and Cardiovascular Disease. JAMA 1979, 241, 2035-2038. [CrossRef]

9. Lundbæk, K. Diabetic angiopathy: A specific vascular disease. Lancet 1954, 263, 377-379. [CrossRef]

Io. Ponikowski, P.; Voors, A.A.; Anker, S.D.; Bueno, H.; Cleland, J.G.; Coats, A.J.; Falk, V.; Gonzalez-Juanatey, J.R.; Harjola, V.P.; Jankowska, E.A.; et al. 20I6 ESC Guidelines for the diagnosis and treatment of acute and chronic heart failure: The Task Force for the diagnosis and treatment of acute and chronic heart failure of the European Society of Cardiology (ESC) Developed with the special contribution of the Heart Failure Association (HFA) of the ESC. Eur. Heart J. 2016, 37, 2129-2200.

II. Wachter, R.; Shah, S.J.; Cowie, M.R.; Szecsödy, P.; Shi, V.; Ibram, G.; Zhao, Z.; Gong, J.; Klebs, S.; Pieske, B. Angiotensin receptor neprilysin inhibition versus individualized RAAS blockade: design and rationale of the PARALLAX trial. ESC Heart Fail. 2020, 7, 856-864. [CrossRef] [PubMed]

I2. Boonman-de Winter, L.J.; Rutten, F.H.; Cramer, M.J.M.; Landman, M.J.; Liem, A.H.; Rutten, G.E.H.M.; Hoes, A.W. High prevalence of previously unknown heart failure and left ventricular dysfunction in patients with type 2 diabetes. Diabetologia 2012, 55, 2154-2162. [CrossRef] [PubMed]

13. Preiss, D.; Zetterstrand, S.; McMurray, J.J.; Östergren, J.; Michelson, E.L.; Granger, C.B.; Yusuf, S.; Swedberg, K.; Pfeffer, M.A.; Gerstein, H.C.; et al. Predictors of Development of Diabetes in Patients With Chronic Heart Failure in the Candesartan in Heart Failure Assessment of Reduction in Mortality and Morbidity (CHARM) Program. Diabetes Care 2009, 32, 915-920. [CrossRef] [PubMed]

I4. Preiss, D.; Van Veldhuisen, D.J.; Sattar, N.; Krum, H.; Swedberg, K.; Shi, H.; Vincent, J.; Pocock, S.J.; Pitt, B.; Zannad, F.; et al. Eplerenone and new-onset diabetes in patients with mild heart failure: results from the Eplerenone in Mild Patients Hospitalization and Survival Study in Heart Failure (EMPHASIS-HF). Eur. J. Heart Fail. 2012, 14, 909-915. [CrossRef] [PubMed]

15. Erqou, S.; Lee, C.-T.C.; Suffoletto, M.; Echouffo-Tcheugui, J.B.; De Boer, R.A.; Van Melle, J.P.; Adler, A.I. Association between glycated haemoglobin and the risk of congestive heart failure in diabetes mellitus: systematic review and meta-analysis. Eur. J. Heart Fail. 2013, 15, 185-193. [CrossRef] [PubMed]

I6. Castagno, D.; Baird-Gunning, J.; Jhund, P.S.; Zoccai, G.B.; Macdonald, M.R.; Petrie, M.C.; Gaita, F.; McMurray, J.J. Intensive glycemic control has no impact on the risk of heart failure in type 2 diabetic patients: Evidence from a 37,229 patient meta-analysis. Am. Heart J. 2011, 162, 938-948.e2. [CrossRef]

17. Aguilar, D.; Bozkurt, B.; Ramasubbu, K.; Deswal, A. Relationship of Hemoglobin ArC and Mortality in Heart Failure Patients With Diabetes. J. Am. Coll. Cardiol. 2009, 54, 422-428. [CrossRef]

I8. From, A.M.; Leibson, C.L.; Bursi, F.; Redfield, M.M.; Weston, S.A.; Jacobsen, S.J.; Rodeheffer, R.J.; Roger, V.L. Diabetes in Heart Failure: Prevalence and Impact on Outcome in the Population. Am. J. Med. 2006, 119, 59I-599. [CrossRef]

19. Dunlay, S.M.; Redfield, M.M.; Weston, S.A.; Therneau, T.M.; Long, K.H.; Shah, N.D.; Roger, V.L. Hospitalizations after heart failure diagnosis a community perspective. J. Am. Coll. Cardiol. 2009, 54, 1695-1702. [CrossRef]

2o. Cosentino, F.; Grant, P.J.; Aboyans, V.; Bailey, C.J.; Ceriello, A.; Delgado, V.; Federici, M.; Filippatos, G.; Grobbee, D.E.; Hansen, T.B.; et al. 2019 ESC Guidelines on diabetes, pre-diabetes, and cardiovascular diseases developed in collaboration with the EASD. Eur. Heart J. 2020, 41, 255-323. [CrossRef]

2I. Cefalu, W.T.; Kaul, S.; Gerstein, H.C.; Holman, R.R.; Zinman, B.; Skyler, J.S.; Green, J.B.; Buse, J.B.; Inzucchi, S.E.; Leiter, L.A.; et al. Cardiovascular Outcomes Trials in Type 2 Diabetes: Where Do We Go From Here? Reflections From aDiabetes CareEditors' Expert Forum. Diabetes Care 2017, 41, I4-31. [CrossRef] [PubMed]

22. Schnell, O.; Rydén, L.; Standl, E.; Ceriello, A.; on behalf of the D\&CVD EASD Study Group. Current perspectives on cardiovascular outcome trials in diabetes. Cardiovasc. Diabetol. 2016, 15, 139. [CrossRef]

23. Neal, B.; Perkovic, V.; Mahaffey, K.W.; De Zeeuw, D.; Fulcher, G.; Erondu, N.; Shaw, W.; Law, G.; Desai, M.; Matthews, D.R. Canagliflozin and Cardiovascular and Renal Events in Type 2 Diabetes. N. Engl. J. Med. 2017, 377, 644-657. [CrossRef] [PubMed]

24. Ghosh, R.K.; Ghosh, S.M.; Chawla, S.; Jasdanwala, S.A. SGLT2 Inhibitors: A New Emerging Therapeutic Class in the Treatment of Type 2 Diabetes Mellitus. J. Clin. Pharmacol. 2012, 52, 457-463. [CrossRef]

25. Abdul-Ghani, M.; A DeFronzo, R. Dapagliflozin for the treatment of type 2 diabetes. Expert Opin. Pharmacother. 2013, 14, 1695-703. [CrossRef] [PubMed]

26. List, J.F.; Whaley, J.M. Glucose dynamics and mechanistic implications of SGLT2 inhibitors in animals and humans. Kidney Int. 2011, 79, S20-S27. [CrossRef]

27. Vasilakou, D.; Karagiannis, T.; Athanasiadou, E.; Mainou, M.; Liakos, A.; Bekiari, E.; Sarigianni, M.; Matthews, D.R.; Tsapas, A. Sodium-glucose cotransporter 2 inhibitors for type 2 diabetes: a systematic review and meta-analysis. Ann. Intern. Med. 2013, 159, 262-274. [CrossRef] 
28. Peters, A.L.; Buschur, E.O.; Buse, J.B.; Cohan, P.; Diner, J.C.; Hirsch, I.B. Euglycemic Diabetic Ketoacidosis: A Potential Complication of Treatment With Sodium-Glucose Cotransporter 2 Inhibition. Diabetes Care 2015, 38, 1687-1693. [CrossRef]

29. Fralick, M.; Schneeweiss, S.; Patorno, E. Risk of Diabetic Ketoacidosis after Initiation of an SGLT2 Inhibitor. N. Engl. J. Med. 2017, 376, 2300-2302. [CrossRef]

30. Zinman, B.; Wanner, C.; Lachin, J.M.; Fitchett, D.; Bluhmki, E.; Hantel, S.; Mattheus, M.; Devins, T.; Johansen, O.E.; Woerle, H.J.; et al. Empagliflozin, Cardiovascular Outcomes, and Mortality in Type 2 Diabetes. N. Engl.J. Med. 2015, 373, 2117-2128. [CrossRef]

31. Inzucchi, S.E.; Zinman, B.; Fitchett, D.; Wanner, C.; Ferrannini, E.; Schumacher, M.; Schmoor, C.; Ohneberg, K.; Johansen, O.E.; George, J.T.; et al. How Does Empagliflozin Reduce Cardiovascular Mortality? Insights From a Mediation Analysis of the EMPA-REG OUTCOME Trial. Diabetes Care 2017, 41, 356-363. [CrossRef] [PubMed]

32. Wiviott, S.D.; Raz, I.; Bonaca, M.P.; Mosenzon, O.; Kato, E.T.; Cahn, A.; Silverman, M.G.; Zelniker, T.A.; Kuder,J.F.; Murphy, S.A.; et al. Dapagliflozin and Cardiovascular Outcomes in Type 2 Diabetes. N. Engl. J. Med. 2019, 380, 347-357. [CrossRef] [PubMed]

33. Zelniker, T.A.; Braunwald, E. Clinical Benefit of Cardiorenal Effects of Sodium-Glucose Cotransporter 2 Inhibitors. J. Am. Coll. Cardiol. 2020, 75, 435-447. [CrossRef] [PubMed]

34. Uthman, L.; Nederlof, R.; Eerbeek, O.; Baartscheer, A.; Schumacher, C.; Buchholtz, N.; Hollmann, M.W.; Coronel, R.; Weber, N.C.; Zuurbier, C.J. Delayed ischaemic contracture onset by empagliflozin associates with NHEI inhibition and is dependent on insulin in isolated mouse hearts. Cardiovasc. Res. 2019, 115, 1533-1545. [CrossRef]

35. Packer, M. Reconceptualization of the Molecular Mechanism by Which Sodium-Glucose Cotransporter 2 Inhibitors Reduce the Risk of Heart Failure Events. Circulation 2019, 140, 443-445. [CrossRef]

36. Uthman, L.; Baartscheer, A.; Bleijlevens, B.; Schumacher, C.A.; Fiolet, J.W.T.; Koeman, A.; Jancev, M.; Hollmann, M.W.; Weber, N.C.; Coronel, R.; et al. Class effects of SGLT2 inhibitors in mouse cardiomyocytes and hearts: inhibition of $\mathrm{Na}+\mathrm{H}+$ exchanger, lowering of cytosolic $\mathrm{Na}+$ and vasodilation. Diabetologia 2017, 61, 722-726. [CrossRef]

37. Scheen, A. Effect of SGLT2 Inhibitors on the Sympathetic Nervous System and Blood Pressure. Curr. Cardiol. Rep. 2019, 21, 70. [CrossRef]

38. Matthews, V.B.; Elliot, R.H.; Rudnicka, C.; Hricova, J.; Herat, L.; Schlaich, M.P. Role of the sympathetic nervous system in regulation of the sodium glucose cotransporter 2. J. Hypertens. 2017, 35, 2059-2068. [CrossRef]

39. Gormsen, L.C.; Svart, M.; Thomsen, H.H.; Søndergaard, E.; Vendelbo, M.H.; Christensen, N.; Tolbod, L.P.; Harms, H.J.; Nielsen, R.; Wiggers, H.; et al. Ketone Body Infusion With 3-Hydroxybutyrate Reduces Myocardial Glucose Uptake and Increases Blood Flow in Humans: A Positron Emission Tomography Study. J. Am. Heart Assoc. 2017, 6, eooso66. [CrossRef]

40. Sano, M.; Goto, S. Possible Mechanism of Hematocrit Elevation by Sodium Glucose Cotransporter 2 Inhibitors and Associated Beneficial Renal and Cardiovascular Effects. Circulation 2019, 139, 1985-1987. [CrossRef]

4I. Ye, Y.; Bajaj, M.; Yang, H.-C.; Perez-Polo, J.R.; Birnbaum, Y. SGLT-2 Inhibition with Dapagliflozin Reduces the Activation of the Nlrp3/ASC Inflammasome and Attenuates the Development of Diabetic Cardiomyopathy in Mice with Type 2 Diabetes. Further Augmentation of the Effects with Saxagliptin, a DPP4 Inhibitor. Cardiovasc. Drugs Ther. 2017, 31, II9-I32. [CrossRef] [PubMed]

42. El-Daly, M.; Venu, V.K.P.; Saifeddine, M.; Mihara, K.; Kang, S.; Fedak, P.W.; Alston, L.A.; A Hirota, S.; Ding, H.; Triggle, C.R.; et al. Hyperglycaemic impairment of PAR2-mediated vasodilation: Prevention by inhibition of aortic endothelial sodium-glucose-co-Transporter-2 and minimizing oxidative stress. Vasc. Pharmacol. 2018, 109, 56-7I. [CrossRef] [PubMed]

43. Cannon, C.P.; McGuire, D.K.; Pratley, R.; Dagogo-Jack, S.; Mancuso, J.; Huyck, S.; Charbonnel, B.; Shih, W.J.; Gallo, S.; Masiukiewicz, U.; et al. Design and baseline characteristics of the eValuation of ERTugliflozin effIcacy and Safety CardioVascular outcomes trial (VERTIS-CV). Am. Heart J. 2018, 206, II-23. [CrossRef] [PubMed]

44. Investigators V-C. Results of Vertis-CV. Oral presentation at American Diabetes Association Scientific Sessions, June 2020. Available online: https://virtual.lww.com/adazozosessions/pages/home.aspx (accessed on 30 August 2020).

45. Cefalo, C.M.A.; Cinti, F.; Moffa, S.; Impronta, F.; Sorice, G.P.; Mezza, T.; Pontecorvi, A.; Giaccari, A. Sotagliflozin, the first dual SGLT inhibitor: current outlook and perspectives. Cardiovasc. Diabetol. 2019, 18, 20. [CrossRef] [PubMed]

46. Von Lewinski, D.; Gasser, R.; Rainer, P.P.; Huber, M.-S.; Wilhelm, B.; Roessl, U.; Haas, T.; Wasler, A.; Grimm, M.; Bisping, E.; et al. Functional effects of glucose transporters in human ventricular myocardium. Eur.J. Heart Fail. 2010, 12, Io6-II3. [CrossRef] [PubMed]

47. Elfeber, K.; Stümpel, F.; Gorboulev, V.; Mattig, S.; Deussen, A.; Kaissling, B.; Koepsell, H. Na ${ }^{+}$-D-glucose cotransporter in muscle capillaries increases glucose permeability. Biochem. Biophys. Res. Commun. 2004, 314, 30I-305. [CrossRef] [PubMed] 
48. Seidelmann, S.B.; Feofanova, E.; Yu, B.; Franceschini, N.; Claggett, B.; Kuokkanen, M.; Puolijoki, H.; Ebeling, T.; Perola, M.; Salomaa, V.; et al. Genetic Variants in SGLTI, Glucose Tolerance, and Cardiometabolic Risk. J. Am. Coll. Cardiol. 2018, 72, 1763-1773. [CrossRef]

49. Effect of Sotagliflozin on Cardiovascular and Renal Events in Patients with Type 2 Diabetes and Moderate Renal Impairment Who Are at Cardiovascular Risk-Full Text View. Available online: https://clinicaltrials.gov/ct2/ show/NCTo3315143 (accessed on 30 August 2020).

50. American Diabetes Association. 8. Pharmacologic Approaches to Glycemic Treatment: Standards of Medical Care in Diabetes-2018. Diabetes Care 2018, 41, S73-S85. [CrossRef]

5I. Davies, M.J.; D'Alessio, D.A.; Fradkin, J.; Kernan, W.N.; Mathieu, C.; Mingrone, G.; Rossing, P.; Tsapas, A.; Wexler, D.J.; Buse, J.B. Management of hyperglycaemia in type 2 diabetes, 20I8. A consensus report by the American Diabetes Association (ADA) and the European Association for the Study of Diabetes (EASD). Diabetologia 2018, 61, 246I-2498. [CrossRef]

52. Buse, J.B.; Wexler, D.J.; Tsapas, A.; Rossing, P.; Mingrone, G.; Mathieu, C.; D’Alessio, D.A.; Davies, M.J. 2019 Update to: Management of Hyperglycemia in Type 2 Diabetes, 20I8. A Consensus Report by the American Diabetes Association (ADA) and the European Association for the Study of Diabetes (EASD). Diabetes Care 2019, 43, 487-493. [CrossRef]

53. American Diabetes Association. 9. Pharmacologic Approaches to Glycemic Treatment: Standards of Medical Care in Diabetes-2020. Diabetes Care 2020, 43, S98-Siro. [CrossRef] [PubMed]

54. McMurray, J.J.; Solomon, S.D.; Inzucchi, S.E.; Køber, L.; Kosiborod, M.N.; Martinez, F.A.; Ponikowski, P.; Sabatine, M.S.; Anand, I.S.; Bělohlávek, J.; et al. Dapagliflozin in Patients with Heart Failure and Reduced Ejection Fraction. N. Engl. J. Med. 2019, 381, 1995-2008. [CrossRef]

55. Inzucchi, S.E. Metabolic Outcomes, Diabetes Prevention \& Safety. Presentation at ADA Scientific Sessions 2020. Update-Have We Lost SGLT2 Inhibitors to Cardiologists?!. Available online: https://virtual.lww.com/ ada2020sessions/pages/home.aspx (accessed on 30 August 2020).

56. Kaplinsky, E. DAPA-HF trial: Dapagliflozin evolves from a glucose-lowering agent to a therapy for heart failure. Drugs Context 2020, 9, I-7. [CrossRef]

57. Nassif, M.E.; Windsor, S.L.; Tang, F.; Khariton, Y.; Husain, M.; Inzucchi, S.E.; Mc-Guire, D.K.; Pitt, B.; Scirica, B.M.; Austin, B.; et al. Dapagliflozin Effects on Biomarkers, Symptoms, and Functional Status in Patients With Heart Failure With Reduced Ejection Fraction. Circulation 2019, 140, I463-I476. [CrossRef]

58. DAPACARE PROGRAMME. Available online: https://azcvrm.co.za/dapa/dapamech (accessed on 30 August 2020).

59. Testani, J.M. Independent Commentary-Implications for Clinical Care and Future Directions. ADA 2020 Presentation. DAPA-HF Update-Have We Lost SGLT2 Inhibitors to Cardiologists?!. Available online: https://virtual.lww.com/adazozosessions/pages/home.aspx (accessed on 30 August 2020).

6o. Packer, M.; Anker, S.D.; Butler, J.; Filippatos, G.; Pocock, S.J.; Carson, P.; Januzzi, J.; Verma, S.; Tsutsui, H.; Brueckmann, M.; et al. Cardiovascular and Renal Outcomes with Empagliflozin in Heart Failure. N. Engl. J. Med. 2020. [CrossRef]

6I. Metra, M. Hot Line EMPEROR-Reduced. Discussion. Presentation at the 2020 ESC Congress. Available online: https://www.escardio.org/Congress-Home (accessed on 30 August 2020).

62. McMurray, J.J.V. Learning from DAPA-HF one year on: Expert on the spot. Presentation at the 2020 ESC Congress. Available online: https://www.escardio.org/Congress-Home (accessed on 30 August 2020).

63. EMPagliflozin outcomE tRial in Patients With chrOnic heaRt Failure with Preserved Ejection Fraction (EMPEROR-Preserved). Available online: https://clinicaltrials.gov/ct2/show/NCT0305795I (accessed on 30 August 2020).

64. FDA Approves New Treatment for a Type of Heart Failure. Available online: https://www.fda.gov/newsevents/press-announcements/fda-approves-new-treatment-type-heart-failure (accessed on 30 August 2020).

65. Packer, M. Hot Line EMPEROR-Reduced. Empagliflozin in heart failure with a reduced ejection fraction, with and without diabetes. Presentation at the 2020 ESC Congress. Available online: https://www.escardio.org/ Congress-Home (accessed on 30 August 2020).

66. Vaduganathan, M.; Claggett, B.L.; Jhund, P.S.; Cunningham, J.W.; Ferreira, J.P.; Zannad, F.; Packer, M.; Fonarow, G.C.; McMurray, J.J.V.; Solomon, S.D. Estimating lifetime benefits of comprehensive disease-modifying pharmacological therapies in patients with heart failure with reduced ejection fraction: a comparative analysis of three randomised controlled trials. Lancet 2020, 396, 12I-128. [CrossRef]

67. Jarcho, J.A. More Evidence for SGLT2 Inhibitors in Heart Failure. N. Engl. J. Med. 2020. [CrossRef]

68. O’Meara, E.; McDonald, M.; Chan, M.; Ducharme, A.; Ezekowitz, J.A.; Giannetti, N.; Grzeslo, A.; Heckman, G.A.; Howlett, J.G.; Koshman, S.L.; et al. CCS/CHFS Heart Failure Guidelines: Clinical Trial Update on Functional Mitral Regurgitation, SGLT2 Inhibitors, ARNI in HFpEF, and Tafamidis in Amyloidosis. Can. J. Cardiol. 2020, 36, 159-169. [CrossRef] [PubMed]

(C) 2020 Copyright by the authors. Licensed as an open access article using a CC BY 4.0 license.

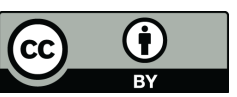

